\title{
Factors contributing to a striking shift in human- wildlife dynamics in Hemis National Park, India: 22 years of reported snow leopard depredation- CORRIGENDUM
}

\author{
Pushinder S. Jamwal, Jigmet Takpa and Michael H. Parsons
}

DOI: 10.1017/S0030605317001892. Published online by Cambridge University Press 15 April 2018

In Fig. 1 of Jamwal et al. (2018) the international borders were depicted incorrectly in the inset map. The correct figure is provided here. The international boundaries in this figure were taken from the 1:10 million breakaway and disputed areas shapefile provided by NaturalEarth (2018).

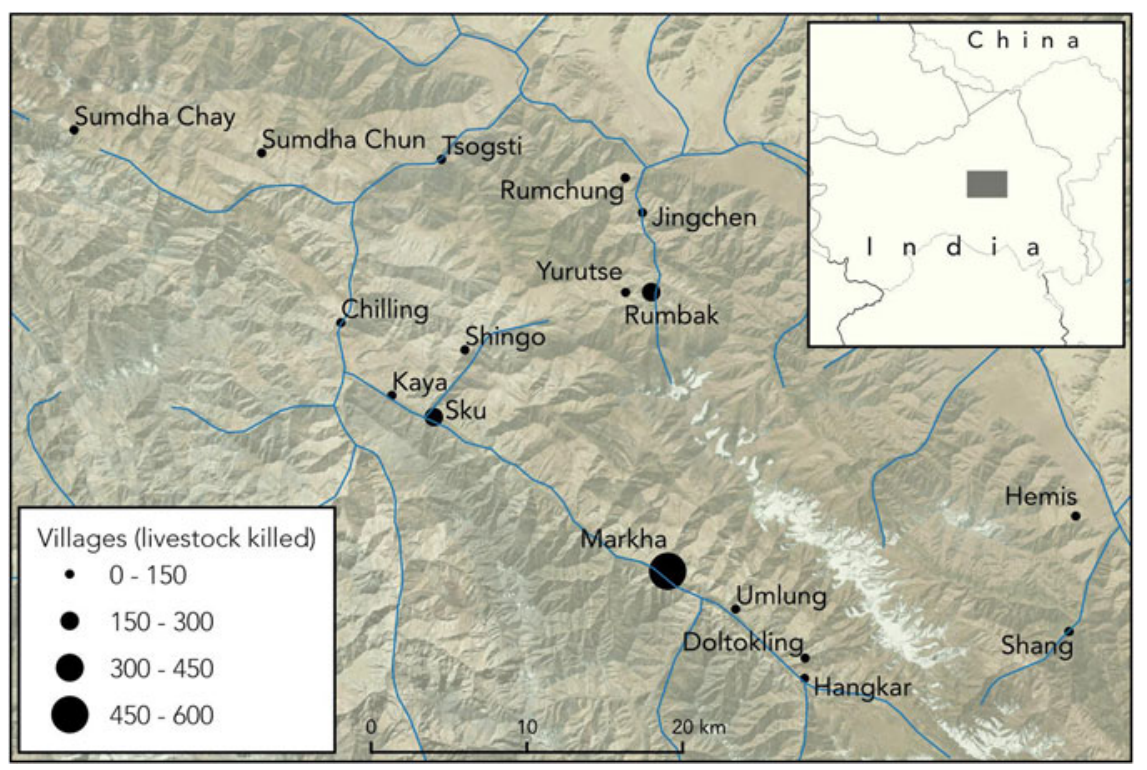

FIG. 1 Hemis National Park and associated villages, with the total number of depredation events by snow leopards Panthera uncia, as reported per village during 1992-2013 (circle size is proportional to the number of events).

\section{References}

Jamwal, P.S., TAKPA, J. \& Parsons, M.H. (2018) Factors contributing to a striking shift in human-wildlife dynamics in Hemis National Park, India: 22 years of reported snow leopard depredation. Oryx, https://doi.org/10.1017/So030605317001892.

NaturalEarth (2018) 1:10m Cultural Vectors. Https://www.natural earthdata.com/downloads/10m-cultural-vectors/ [accessed 13 July 2018]. 